\title{
Withania somnifera Root Extract Enhances Telomerase Activity in the Human HeLa Cell Line
}

\author{
Vasantharaja Raguraman, Jamuna R. Subramaniam* \\ Center for Preclinical and Translational Medicine Research, Central Research Facility, \\ Sri Ramachandra University, Chennai, India \\ Email: *jamuna17@sriramachandra.edu.in
}

Received 10 March 2016; accepted 12 April 2016; published 15 April 2016

Copyright (C) 2016 by authors and Scientific Research Publishing Inc.

This work is licensed under the Creative Commons Attribution International License (CC BY).

http://creativecommons.org/licenses/by/4.0/

(c) (i) Open Access

\begin{abstract}
Aging is a decelerating unidirectional process of life. Shortening of telomeric DNA, the (TTAGGG) hexanucleotide repeats, which form the caps at the chromosome ends, is implicated to determine the aging process, and more importantly the healthy lifespan itself. Telomerase, a ribonucleoprotein having reverse transcriptase activity, arrests telomere loss through addition of the TTAGGG repeats de novo, to the ends of the chromosome. The telomere/telomerase maintenance is an inevitable necessity to delay aging and for a healthy lifespan. Here, we report the potential of full-spectrum, high concentration Ashwagandha (Withania somnifera), an Ayurvedic medicinal herb, root extract to increase telomerase activity. HeLa cells, when treated with various concentrations of Ashwagandha root extract, showed an increase in telomerase activity measured with the established Telomerase Rapid Amplification Protocol (TRAP) assay. Ashwagandha root extract increased telomerase activity with highest enhancement of $\sim 45 \%$ at 10 - $50 \mu$ g concentration. Thus, Ashwagandha root extract has the anti-aging inducing potential.
\end{abstract}

\section{Keywords}

Ashwagandha, Telomerase, HeLa Cell Line, TRAP Assay

\section{Introduction}

Aging, the relentless decelerating phenomenon, is the main cause for wide range of age-associated diseases like cancer, ischemic heart disease, stroke, type 2 diabetes, neurodegenerative diseases including Alzheimer's disease and others [1]. One of the major factors that accelerate aging and cause degeneration of various systems is

*Corresponding author.

How to cite this paper: Raguraman, V. and Subramaniam, J.R. (2016) Withania somnifera Root Extract Enhances Telomerase Activity in the Human HeLa Cell Line. Advances in Bioscience and Biotechnology, 7, 199-204.

http://dx.doi.org/10.4236/abb.2016.74018 
the shortening of "TELOMERES", the DNA repeat sequences at the end of linear eukaryotic chromosomes, of 2 - $20 \mathrm{kbp}$ length, which act as caps to conserve chromosome integrity and stability [2]. During the process of DNA replication, telomeres are shortened by 50 - 100 bp with each cell division. The end replication problem leads to critically short telomeres and ultimately senescence. Hence, telomeres are implicated as one of the factors that determine aging and lifespan. The enzyme, telomerase, a ribonucleoprotein having reverse transcriptase activity, carries out telomere replication. Telomerase synthesizes telomeric DNA sequences through the addition of TTAGGG repeats at the chromosome ends [3]. But, the telomerase activity is extremely low in somatic cells.

Telomerase is shown to be essential for the healthy normal life. Turning off of the telomerase expression in the conditional knockout mice leads to degeneration of multiple systems, including immune, digestive and nervous system. When telomerase expression is turned on later in life, these degenerations can be reversed. More importantly, nervous system, where neurons are thought to be differentiated and stay that way for a lifetime, manifests remarkable improvement from the degeneration [4]. Telomerase activity and short telomeres are implicated in aging mechanism [5]-[7]. Enhancing telomerase activity is one way to delay aging. A small molecule telomerase activator, TA-65, isolated from the root of the traditional Chinese medicine, Astragalus membranaceus in mice [8] can precisely do the same.

Ashwagandha (Withania somnifera Dunal) root extract, consisting of several withanolides, is an extensively used ayurvedic medicine with multitude of protective effects on humans such as revitalization, stress tolerance [9] and anti-inflammation [10]. Further, it enhances longevity in C. elegans [11]. With little or no toxic effect, Ashwagandha [12] can be considered as supplement in humans [13]. Though Ashwagandha is suggested to increase longevity, so far no evidence has been provided to reinforce this claim except in C. elegans [11] which is usually a harbinger to the positive outcome in humans.

Here, we address the efficacy of a high concentration, full-spectrum Ashwagandha root extract to provide anti-aging effect through enhanced telomerase activity in an in vitro cell culture model.

\section{Materials and Methods}

\subsection{Cell Culture}

The human HeLa cell line was used in the present study. The cells were maintained in DMEM (Invitrogen) supplemented with $10 \%$ fetal bovine serum in a humidified incubator $\left(37^{\circ} \mathrm{C}\right.$ and $\left.5 \% \mathrm{CO}_{2}\right)$. Cells $(40 \%-60 \%$ confluency) were treated with various concentrations (10 $\mu \mathrm{g}, 50 \mu \mathrm{g}, 100 \mu \mathrm{g}, 500 \mu \mathrm{g}, 5 \mathrm{mg})$ of Ashwagandha Root Extract (KSM-66, Shri Kartikeya Pharma, Hyderabad) for 72 hours.

\subsection{Preparation of Cell Lysate}

Cells were collected and centrifuged at $6000 \mathrm{rpm}$ for $6 \mathrm{~min}$. Pellets of $6 \times 10^{5}$ cells were suspended in ice-cold NP-40 lysis buffer and incubated 30 min on ice [14]. The cell lysate was aliquoted into separate tubes and stored at $-80^{\circ} \mathrm{C}$ until analyzed by TRAP assay.

\subsection{Telomerase Assay and Quantification}

Detection of telomerase activity in HeLa extracts employed the PCR-based telomeric repeat amplification protocol (TRAP assay) is a modification of the assay described by [14]. The protein concentration was determined using Lowry's method [15]. Briefly, total volume of reaction mixture was $50 \mu \mathrm{l}$ contained $0.5 \mu \mathrm{l}$ of dNTP mix (2.5 mM), $5 \mu \mathrm{l}$ of 10× TRAP Buffer, $0.15 \mu \mathrm{g}$ TS [5'-AATCCGTCGAGCAGAGTT-3'] primer, $0.15 \mu \mathrm{g}$ and ACX [5'GCGCGGCTTACCCTTACCCTTACCCTAACC-3'] primer, $40 \mu \mathrm{l}$ RNase-free H2O, $0.5 \mu \mathrm{l}$ of $5 \mathrm{U} / \mu \mathrm{l}$ Taq DNA polymerase and $2 \mu \mathrm{l}$ (1000 cells) of cell lysate. The PCR mixture was incubated at $30 \mathrm{~min}$ at room temperature. The PCR was then started at $94^{\circ} \mathrm{C}$ for 90 sec followed by a 40 -cycle amplification $\left(94^{\circ} \mathrm{C}\right.$ for $20 \mathrm{~s}$, $50^{\circ} \mathrm{C}$ for $30 \mathrm{~s}$, and $72^{\circ} \mathrm{C}$ for $90 \mathrm{~s}$ ). The amplified PCR product will yield a 6-bp incremental ladder was separated on $12 \%$ acrylamide-TBE gels and visualized by ethidium bromide staining in UV light. The images were then processed and quantified using Image J software. The density/intensity of the amplified 6 bp repeat periodicity PCR product observed and quantitated by Image J software is represented as densitometric units.

\subsection{Statistical Analysis}

Statistical analyses on the percentage of telomerase activity in HeLa cell extracts were done using Sigmaplot 
(ver.10.0).

\section{Results}

Aging associated telomere shortening is well documented. More importantly, telomerase, which is needed to maintain the telomere length through replication, is essential for healthy life. In the terminally differentiated somatic tissues, telomerase activity is low. Several factors, including stress aggravate the senescence process through telomere shortening. Given the importance of telomere/telomerase in aging and health, identification of a supplement from the natural/plant herb based ancient traditional systems of medicine, which could retain the telomere length or increase telomerase activity, is a less expensive and faster way with the most important added benefit of dismal toxicity. We evaluated the Ashwagandha root extract powder (KSM-66) suspended in water to enhance telomerase activity. Using the human cervical carcinoma cell line, HeLa, reported to have telomerase activity [16], we determined Ashwagandha's telomerase activity enhancing effect following published protocols [14]. First of all, we determined the optimal total protein concentration of the cell extract needed to assess the telomerase activity (Figure 1). The telomerase activity was highest between $50 \mathrm{ng}$ and $5 \mu \mathrm{g}$ of total protein of cell extract. We selected $2 \mu \mathrm{g}$ as the ideal protein concentration and all further telomerase assays were carried out under these conditions.

\subsection{Identification of Optimal Concentration of Ashwagandha to Enhance Telomerase Activity}

HeLa cells were exposed to different concentrations of full spectrum Ashwagandha root extract as suspension of the powder in water for 72 hrs following which the cells were processed and telomerase activity determined. This resulted in dose-dependent increase in telomerase activity upto $50 \mu \mathrm{g} / \mathrm{ml}$ after which the activity started decreasing as the preparation is a powder suspension (Figure 2).

\subsection{Enhancement of Telomerase Activity}

Further, HeLa cells were treated with $10 \mu \mathrm{g}$ and $50 \mu \mathrm{g}$ of Ashwagandha root extract based on results arrived from dose response curve. Cells treated with 10 - 50 g of Ashwagandha root extract enhanced telomerase activity by $45 \%$ (Figure 3 ).

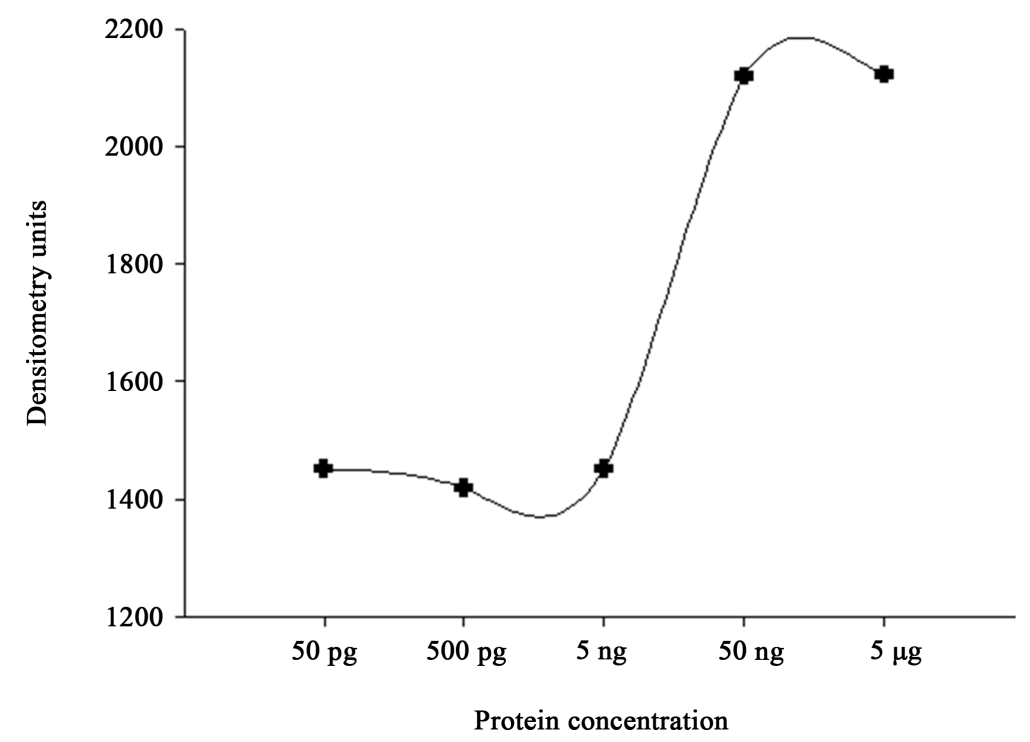

Figure 1. Determination of optimal concentration for the telomerase assay. Different concentrations of HeLa cell lysates were assayed for telomerase activity. The activity is measured by quantifying the density of amplified 6 bp repeats under each concentration with Image $\mathrm{J}$ software and represented as densitometric units in the $\mathrm{Y}$-axis. X-axis represents the amount of total HeLa cell lysate as protein concentration. 


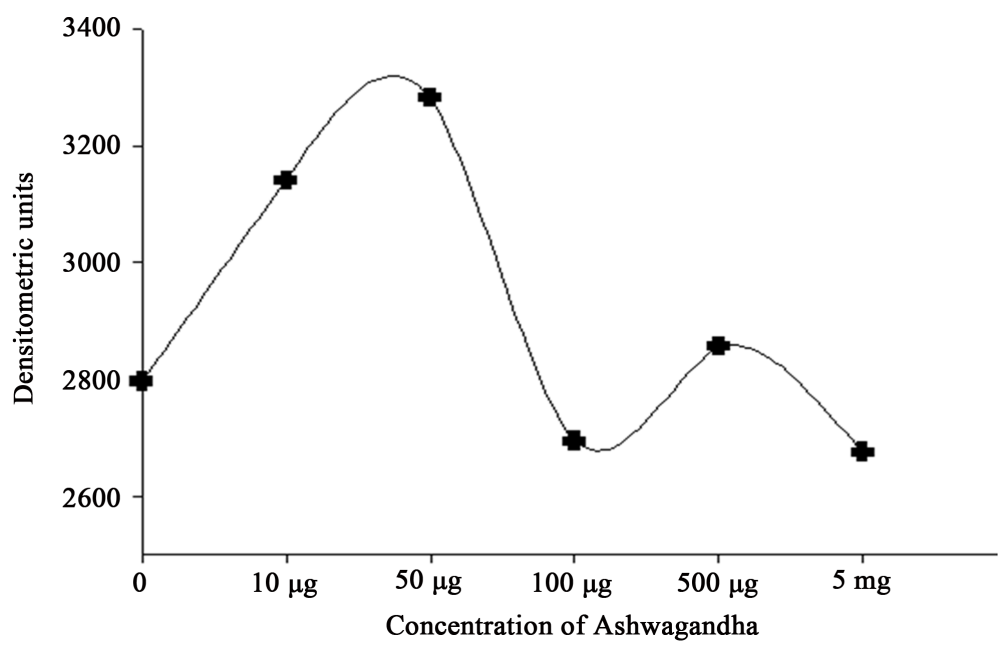

Figure 2. Effect of various concentrations of Ashwagandha root extract on telomerase activity in HeLa cells. The concentrations of Ashwagandh is given in the X-axis. The telomerase activity measured by quantifying the density of amplified 6 bp repeats (resolved in the $12 \%$ TBE-acrylamide gel), under each concentration with Image J software and represented as densitometric units in the Y-axis.

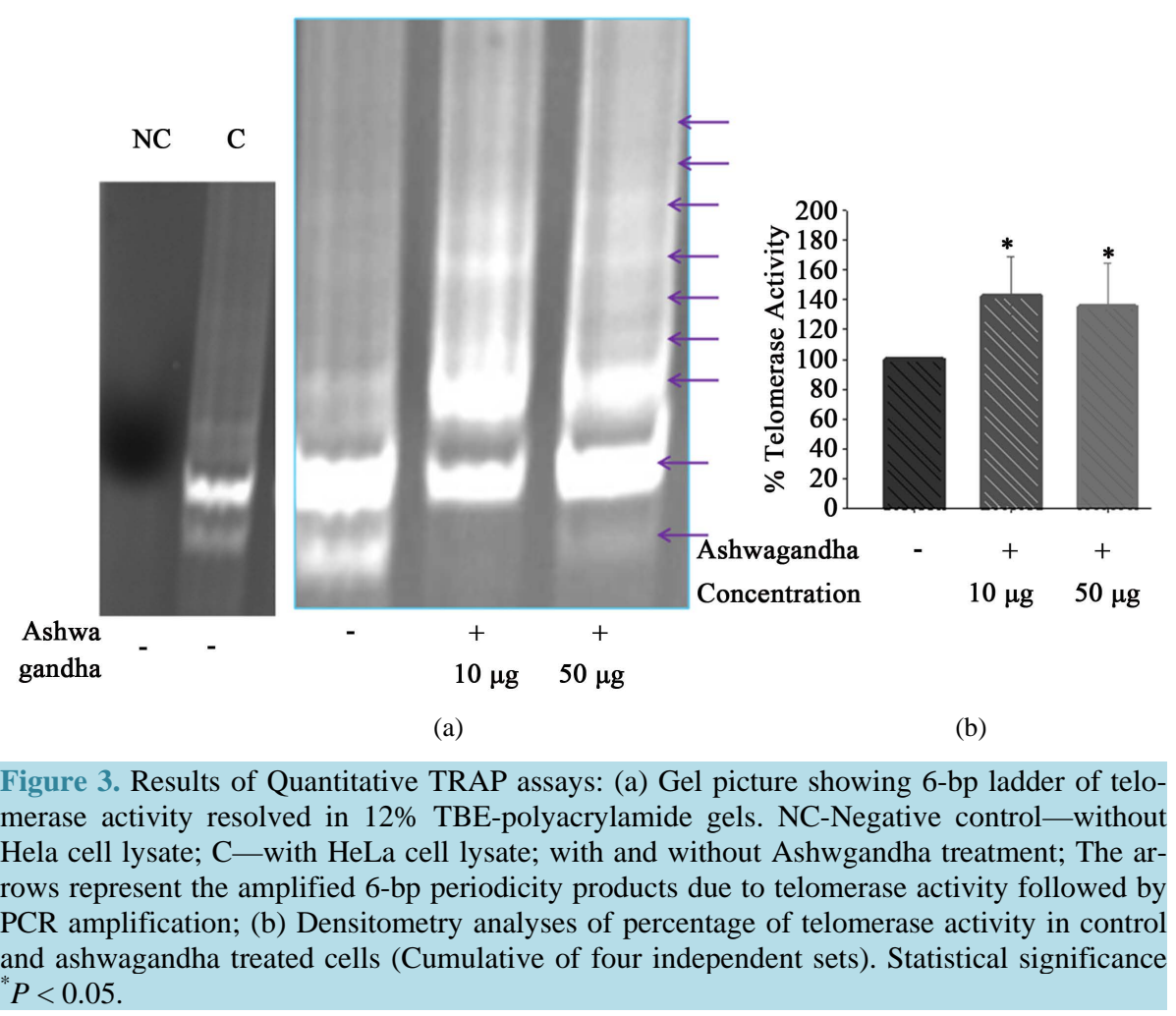

\section{Discussion}

As non communicable diseases are in the rise due to aging, strategies to increase healthspan is rigorously evaluated using all possible systems and organisms. Generally, a gene or its absence or specific chemicals like Reserpine [17] [18], Aswagandha [11], Rapamycin [19] and Resveratrol [20] can increase lifespan in various organisms like yeast, C. elegans, drosophila and mice. In addition, they induce stress tolerance. But the exact mechanism of their lifespan extension, especially the contribution of telomere/telomerase is not known. One of the 
important qualities for health span is stable telomere at the ends of the chromosomes in the differentiated somatic tissues. The hallmark of aging is associated with telomere; the progressive attrition of telomere in human beings contributes to mortality in several age-related diseases [6] [21]. Mouse cells without telomerase activity have short telomere length [22], emphasizing the essentiality of telomerase for telomere maintenance. Since aging promotes degenerative pathologies, screening for new drugs is a necessity to develop highly effective therapy for the enhancement of telomerase activity in order to avoid critically short telomere length leading to aging and age-related diseases. Tomás-Loba et al., (2008) [23] demonstrated that enhanced telomerase activity in mice can delay aging and confer cancer resistance. Recently, Bernardes de Jesus et al., (2011), demonstrated TA-65 [8], the telomerase activator obtained from the Chinese medicine, can elongate short telomeres and increase health span of mice without increasing cancer incidence. Hence, we evaluated the enhancement of the telomerase activity, which is to maintain the telomere by adding the hexanucleotide repeats, by an ancient Ayurvedic herb Ashwagandha root extract (Figure 1). Indeed, Ashwagandha root extract powder, at a concentration of 10 $\mu \mathrm{g}-50 \mu \mathrm{g} / \mathrm{ml}$ (Figure 2), increased telomerase activity by 45\%, in the Human HeLa cell line upon 72 hrs exposure (Figure 3), as determined by the TRAP assay. Ashwagandha is one of the most widely used ancient ayurvedic herb and generally non-toxic. Moreover, earlier, we reported that Ashwagandha can increase C. elegans lifespan [11]. Therefore, Ashwagandha deserves to be evaluated as a potential anti-aging ayurvedic herbal preparation in higher organisms and the potential mechanism needs to be investigated.

\section{Conclusion}

Thus, Ashwagandha root extract is able to enhance telomerase activity in the HeLa cell line. Given the exceptional necessity of the telomeres at the ends of the chromosomes for the maintenance and integrity of the chromosomes, it will be worthwhile to evaluate Ashwagandha under various adult onset disease conditions. This can provide a holistic protective effect.

\section{Acknowledgements}

The authors thank the Center for Stem Cell and Regenerative Medicine and the Center for Indian Systems of Medicine, Sri Ramachandra University for the infrastructure and Shri Kartikeya Pharma, Hyderabad for the financial support.

\section{References}

[1] Jin, K., Simpkins, J.W., Ji, X., Leis, M. and Stambler, I. (2015) The Critical Need to Promote Research of Aging and Aging-Related Diseases to Improve Health and Longevity of the Elderly Population. Aging and Disease, 6, 1-5. http://dx.doi.org/10.14336/AD.2014.1210

[2] Blackburn, E.H. (2001) Switching and Signaling at the Telomere. Cell, 106, 661-673. http://dx.doi.org/10.1016/S0092-8674(01)00492-5

[3] Greider, C.W. and Blackburn, E.H. (1985) Identification of a Specific Telomere Terminal Transferase Activity in Tetrahymena Extracts. Cell, 43, 405-413. http://dx.doi.org/10.1016/0092-8674(85)90170-9

[4] Jaskelioff, M., Muller, F.L., Paik, J.-H., et al. (2011) Telomerase Reactivation Reverses Tissue Degeneration in Aged Telomerase-Deficient Mice. Nature, 469, 102-126. http://dx.doi.org/10.1038/nature09603

[5] Flores, I., Benetti, R. and Blasco, M.A. (2006) Telomerase Regulation and Stem Cell Behaviour. Current Opinion in Cell Biology, 18, 254-260. http://dx.doi.org/10.1016/j.ceb.2006.03.003

[6] Harley, C.B., Futcher, A.B. and Greider, C.W. (1990) Telomeres Shorten during Ageing of Human Fibroblasts. Nature, 345, 458-460. http://dx.doi.org/10.1038/345458a0

[7] Mu, J. and Wei, L.X. (2002) Telomere and Telomerase in Oncology. Cell Research, 12, 1-7. http://dx.doi.org/10.1038/sj.cr.7290104

[8] de Jesus, B.B., Schneeberger, K., Vera, E., Tejera, A., Harley, C.B. and Blasco, M.A. (2011) The Telomerase Activator TA-65 Elongates Short Telomeres and Increases Health Span of Adult/Old Mice without Increasing Cancer Incidence. Aging Cell, 10, 604-621. http://dx.doi.org/10.1111/j.1474-9726.2011.00700.x

[9] Bhattacharya, S.K. and Muruganandam, A.V. (2003) Adaptogenic Activity of Withania somnifera: An Experimental Study Using a Rat Model of Chronic Stress. Pharmacology Biochemistry and Behavior, 75, 547-555. http://dx.doi.org/10.1016/S0091-3057(03)00110-2

[10] Malik, F., Kumar, A., Bhushan, S., et al. (2009) Immune Modulation and Apoptosis Induction: Two Sides of Antitu- 
moural Activity of a Standardised Herbal Formulation of Withania somnifera. European Journal of Cancer, 45, 14941509. http://dx.doi.org/10.1016/j.ejca.2009.01.034

[11] Kumar, R., Gupta, K., Saharia, K., Pradhan, D. and Subramaniam, J.R. (2013) Withania somnifera Root Extract Extends Lifespan of Caenorhabditis elegans. Annals of Neuorscience, 20, 13-16.

[12] Prabu, P.C., Panchapakesan, S. and Raj, C.D. (2013) Acute and Sub-Acute Oral Toxicity Assessment of the Hydroalcoholic Extract of Withania somnifera Roots in Wistar Rats. Phytotherapy Research, 27, 1169-1178.

[13] Mishra, L.C., Singh, B.B. and Dagenais, S. (2000) Scientific Basis for the Therapeutic Use of Withania somnifera (Ashwagandha): A Review. Alternative Medicine Review, 5, 334-346.

[14] Herbert, B.-S., Shay, J.W. and Wright, W.E. (2003) Analysis of Telomeres and Telomerase. Current Protocols in Cell Biology, Chapter 18, Unit 18.6. http://dx.doi.org/10.1002/0471143030.cb1806s20

[15] Lowry, O.H., Rosebrough, N.J., Farr, A.L. and Randall, R.J. (1951) Protein Measurement with the Folin Phenol Reagent. Journal of Biological Chemistry, 193, 265-275.

[16] Hou, M., Xu, D., Bjorkholm, M. and Gruber, A. (2001) Real-Time Quantitative Telomeric Repeat Amplification Protocol Assay for the Detection of Telomerase Activity. Clinical Chemistry, 47, 519-524.

[17] Srivastava, D., Arya, U., Soundara Rajan, T., Dwivedi, H., Kumar, S. and Subramaniam, J.R. (2008) Reserpine Can Confer Stress Tolerance and Lifespan Extension in the Nematode C. elegans. Biogerontology, 9, 309-316. http://dx.doi.org/10.1007/s10522-008-9139-5

[18] Saharia, K., Arya, U., Kumar, R., Sahu, R., Das, C.K., Gupta, K., Dwivedi, H. and Subramaniam, J.R. (2012) Reserpine Modulates Neurotransmitter Release to Extend Lifespan and Alleviate Age-Dependent A $\beta$ Proteotoxicity in Caenorhabditis elegans. Experimental Gerontology, 47, 188-197. http://dx.doi.org/10.1016/j.exger.2011.12.006

[19] Harrison, D.E., Strong, R., Sharp, Z.D., Nelson, J.F., Astle, C.M., Flurkey, K., Nadon, et al. (2009) Rapamycin Fed Late in Life Extends Lifespan in Genetically Heterogeneous Mice. Nature, 460, 392-395.

[20] Wood, J.G., Rogina, B., Lavu, S., Howitz, K., et al. (2004) Sirtuin Activators Mimic Caloric Restriction and Delay Ageing in Metazoans. Nature, 430, 686-689. http://dx.doi.org/10.1038/nature02789

[21] Cawthon, R.M., Smith, K.R., O’Brien, E., Sivatchenko, A. and Kerber, R.A. (2003) Association between Telomere Length in Blood and Mortality in People Aged 60 Years or Older. The Lancet, 361, 393-395. http://dx.doi.org/10.1016/S0140-6736(03)12384-7

[22] Blasco, M.A., Lee, H.W., Hande, M.P., et al. (1997) Telomere Shortening and Tumor Formation by Mouse Cells Lacking Telomerase RNA. Cell, 91, 25-34. http://dx.doi.org/10.1016/S0092-8674(01)80006-4

[23] Tomás-Loba, A., Flores, I., Fernández-Marcos, P.J., et al. (2008) Telomerase Reverse Transcriptase Delays Aging in Cancer-Resistant Mice. Cell, 135, 609-622. http://dx.doi.org/10.1016/j.cell.2008.09.034 